\title{
OPEN Novel gene rearrangement in the mitochondrial genome of Muraenesox cinereus and the phylogenetic relationship of Anguilliformes
}

Kun Zhang ${ }^{1,3}$, Kehua Zhu $^{1,3}$, Yifan Liu ${ }^{1,3 凶}$, Hua Zhang ${ }^{2}$, Li Gong ${ }^{1,3}$, Lihua Jiang ${ }^{1,3}$, Liqin Liu ${ }^{1,3}$ Zhenming $\mathrm{Lü}^{1,3}$ \& Bingjian Liư ${ }^{1,2,3 凶}$

The structure and gene sequence of the fish mitochondrial genome are generally considered to be conservative. However, two types of gene arrangements are found in the mitochondrial genome of Anguilliformes. In this paper, we report a complete mitogenome of Muraenesox cinereus (Anguilliformes: Muraenesocidae) with rearrangement phenomenon. The total length of the $M$. cinereus mitogenome was $17,673 \mathrm{bp}$, and it contained 13 protein-coding genes, two ribosomal RNAs, 22 transfer RNA genes, and two identical control regions (CRs). The mitochondrial genome of $M$. cinereus was obviously rearranged compared with the mitochondria of typical vertebrates. The genes ND6 and the conjoint trnE were translocated to the location between trnT and trnP, and one of the duplicated CR was translocated to the upstream of the ND6. The tandem duplication and random loss is most suitable for explaining this mitochondrial gene rearrangement. The Anguilliformes phylogenetic tree constructed based on the whole mitochondrial genome well supports Congridae non-monophyly. These results provide a basis for the future Anguilliformes mitochondrial gene arrangement characteristics and further phylogenetic research.

Anguilliformes is a kind of ecologically diverse fish, mainly marine fish. Its body is very slender, its crosssectional area is reduced, and it generally lacks ventral fins ${ }^{1,2}$. Traditional morphological taxonomy divides the eel-shaped order (the largest one) into three sub-orders: Anguilloidei, Congroidei and Muraenoidei ${ }^{3}$. However, previous phylogenetic studies of Anguilliformes relationship based solely on morphological data have failed to resolve the relationship between these three suborders ${ }^{3-5}$. For example, recent molecular analysis based on mitochondrial and nucleic acid data has raised questions about the taxonomic status of Anguilliformes ${ }^{6,7}$. The phylogenetic relationship of Anguilliformes is still unclear. In particular, the family-level classification needs to be revised, because many known families or genera may be multi-lineage, especially the well-known Congridae and Nettastomatidae 8,9 . cinereus belongs to the Muranesox genus in the Muranesocidae family, also known as dagger-tooth pike conger. $M$. cinereus is located as far north as Japan and South Korea, and south as far as the Arafara Sea and North Australia ${ }^{10}$. M. cinereus mainly inhabits soft bottoms, but was also common in estuaries. M. cinereus was an important economic fish and one of the most popular moray eels in China ${ }^{11}$.

Mitochondria was the two layered organelles found in most cells. It was also producing energy in the cell structure and the major site of aerobic respiration. So it was called "power house". The length of vertebrate mitochondria was $16-20 \mathrm{~kb}$, which was usually a typical circular structure, containing 13 protein coding genes (PCGs), 22 tRNA genes (tRNA) and two rRNA genes (rRNA) ${ }^{12,13}$. The order of these genes was initially considered conservative because the mammalian complete mitochondrial genome and the African clawed frog have the same genetic order ${ }^{14-16}$. Mitochondrial genomes were maternally inherited, so the recombination rate was

\footnotetext{
${ }^{1}$ National Engineering Laboratory of Marine Germplasm Resources Exploration and Utilization, Zhejiang Ocean University, No. 1, Haida South Road, Zhoushan, Zhejiang 316022, People's Republic of China. ${ }^{2}$ Key Laboratory of Tropical Marine Bio-Resources and Ecology, Chinese Academy of Sciences, Beijing, People's Republic of China. ${ }^{3}$ National Engineering Research Center for Facilitated Marine Aquaculture, Marine Science and Technology College, Zhejiang Ocean University, Zhoushan 316022, People's Republic of China. ${ }^{\square}$ email: et999927@163.com; bjetbj@163.com
} 
extremely low, and the replacement rate was faster than that of nuclear DNA ${ }^{17}$. Therefore, mitochondrial markers have become the most commonly used inference target for molecular phylogeny of fish species. However, variations in this gene sequence have been found in various vertebrate lineages, including amphibians ${ }^{18,19}$, reptiles ${ }^{20,21}$, $\operatorname{birds}^{22,23}$, marsupials ${ }^{24}$ and fish ${ }^{8,13,25}$. In recent years, with the increase in the number of mitochondrial genome sequencing and the improvement of technology, people have discovered more and more gene rearrangements ${ }^{19-21}$. However, the bony fish with the largest number of published complete mitochondrial genomes showed only a partial gene rearrangement ${ }^{26-28}$. Gong ${ }^{29}$ summarized the complete sequence of 1255 fish mitochondrial genomes in the National Center for Biotechnology Information (NCBI) database, and found that 52 fish species have rearranged mitochondrial genomes, including shuffling, translocation, and inversion, involving 15 subjects and 34 families. The probability of rearrangement of genes in the fish mitochondrial genome is low.

In general, the mitochondrial genome structure of fish, especially in the order of genes, is highly conserved ${ }^{29}$. However, with the gradual increase of mtDNA sequence data of fish, there have been reports of rearrangement of mitogenome ${ }^{18,30-32}$. In general, a bony fish group has only one or a group of similar mitochondrial gene arrangements ${ }^{33}$. However, after comparing the gene rearrangement of the mitochondria of Anguilliformes, we found that there are two different gene rearrangement phenomena: (1) most have the typical vertebrate gene sequence (2) in a few mitochondrial genomes, the ND6 gene combines with trnE was transferred to the position between $\operatorname{trnT}$ and $\operatorname{trn} P$, and accompanied by repetition of $\mathrm{CR}^{13}$.

So far, four main hypotheses have been proposed to explain the gene rearrangement in animal mitochondrial genomes. The first hypothesis is that Poulton first proposed a model of in-patient mitochondrial reorganization when studying patient mitochondria, which is characterized by involvement in DNA strand breakage and reconnection $^{34}$; this hypothesis was originally proposed for gene rearrangement in the nuclear genome ${ }^{35}$. This gene rearrangement model has been used to explain changes in the mitochondrial gene order of mussels, birds and frogs ${ }^{36-38}$. Another commonly accepted assumption is the tandem replication and random loss (TDRL) model, which assumes that rearrangement occurs through the tandem replication of some genes, followed by random deletion of duplicates ${ }^{39,40}$. This model is used to explain the gene rearrangement of vertebrate mitochondrial genome $\mathrm{e}^{41,42}$. Lavrov et $\mathrm{al}^{43}$. proposed this rearrangement model (the tandem duplication and non-random loss) for the first time to explain the mitochondrial gene rearrangement of two kinds of millipedes. The difference between this model and the TDRL model is that this loss is non-random, and it depends on the transcription polarity and location of the gene. Shi et $\mathrm{al}^{27}$. raised a new model, the double replication random loss (DRRL) model to explain the rearrangement of the flatfish Samariscus latus (Samaridae) genome. According to this model, the control region (CR) was usually copied and shifted. Then, the two CRs successively initiated the double replication of the mitochondrial genome, leading to gene replication between the two CRs. Finally, one of each pair of duplicated genes was randomly lost $\mathrm{t}^{27}$.

Previous studies have shown that rearrangement of the mitochondrial genome can provide important clues to the evolution and origin of species ${ }^{44,45}$. In this paper, the gene structure and gene rearrangement of the mitochondrial genome of $M$. cinereus (Anguilliformes, Muraenesocidae) common in Chinese waters were reported, and the relationship between the mitochondrial genome rearrangement and phyletic evolution of Anguilla was further discussed based on previous report. Based on the similarities and differences of the gene rearrangement order in the mitochondrial genome, the possible rearrangement process was discussed in order to have a better understanding of the rearrangement events and evolutionary mechanisms of the eel mitochondrial genome.

\section{Results and discussion}

Genome structure and composition. The complete mitochondrial genome of $M$. cinereus is $17,673 \mathrm{bp}$ (GenBank accession number MT571331), which is within the published length range of the bony fish's mitochondrial genome (16,417-18,369 bp) (Table 1). The structure of the moray mitochondrial genome was different from other bony fishes, it includes 13 PCGs, 22 tRNAs, two rRNAs (12S and 16S rRNA), a light chain replication source $\left(\mathrm{O}_{\mathrm{L}}\right)$ and two control-region s (CR) (Fig. 1). And the gene rearrangement was different from some other fish mitochondria. To be precise, ND6 binding trnE was transferred between $t R N A T$ and $t R N A P$, and a replicated CR was transferred upstream of the ND6 gene (Fig. 1, Table 2). In the vertebrate mitochondrial genome, the presence of replicated CR was considered a special feature ${ }^{46-48}$. The base composition of $M$. inereus mitochondrial genome was: $\mathrm{A}=32.1 \%, \mathrm{~T}=27.6 \%, \mathrm{C}=23.8 \%$ and $\mathrm{G}=16.6 \%$, respectively (Table 3 ). Overall, the mitotic genome was very compact. However, 89 base pairs of 12 gene spacers were found in the mitochondrial genome of moray eel, ranging in length from 1 to $35 \mathrm{bp}$. Most of the gaps were found in the area where rearrangement occurred, including 35 bp between $C y t b$ and $\operatorname{trn} T, 4$ bp between $\operatorname{trnT}$ and $C R 1,1$ bp between $\operatorname{trnE}$ and $\operatorname{trn} P$, and 23 bp between CR2 and trnP. The AT-skew of the mitochondrial genome was positive and the GC-skew was negative, respectively 0.076 and -0.179 , indicating that As and Cs are more abundant than Ts and Gs.

PCGs and codon usage. The total length of the 13 PCGs in the $M$. cinereus mitochondrial genes were $11,454 \mathrm{bp}$, and they encode 3,818 amino acids. Genes encoding 13 proteins include seven NADH dehydrogenases (ND1-ND6 and ND4L), three cytochrome c oxidases (COI-COII), two ATPases (ATP6 and ATP8) and one cytochrome b (cytb). The 13 PCGs range in size from $168 \mathrm{bp}$ (ATP8) to $1857 \mathrm{bp}$ (ND5) (Table 3). Like the typical mitochondrial genome of vertebrates ${ }^{49,50}$, there are twelve genes in the H-strand and only ND6 genes in the L-strand.

The initiation codon of the 13 protein-coding genes used the typical initiation codon ATG, except for GTG for the COI gene. Seven PCGs (ND1, COI, ATP8, ATP6, COIII, ND4L, and ND5) were terminated with a stop codon TAA, three (ND2, ND3, and ND6) were terminated with TAG, and one (Cyt b) was terminated with AGA, in addition, ND4 And COII terminate with an incomplete nucleotide T- (Table 2). This result was very similar to that of $\mathrm{Lu}$ et $\mathrm{al}^{13}$. Whether in invertebrate or vertebrate mitochondrial genes, the presence of incomplete stop codons is 


\begin{tabular}{|c|c|c|c|c|}
\hline Family & Species & Length (bp) & Accession No & References \\
\hline \multirow{2}{*}{ Nemichthyidae } & Nemichthys scolopaceus & 17,457 & NC_013620 & 64 \\
\hline & Labichthys carinatus & 16,683 & NC_013626 & 64 \\
\hline \multirow{2}{*}{ Serrivomeridae } & Serrivomer sector & 16,099 & NC_013436 & 13 \\
\hline & Stermonidium hypomelas & 16,566 & NC_013628 & 13 \\
\hline \multirow{9}{*}{ Anguillidae } & Anguilla dieffenbachi & 16,687 & NC_06538 & 13 \\
\hline & Anguilla megastoma & 16,714 & NC_006541 & 13 \\
\hline & Anguilla japonica & 16,685 & NC_002707 & 13 \\
\hline & Anguilla reinhardti & 16,690 & NC_006546 & 13 \\
\hline & Anguilla marmorata & 16,745 & NC_06540 & 13 \\
\hline & Anguilla interioris & 16,713 & NC_006539 & 13 \\
\hline & Anguilla obscura & 16,704 & NC_006545 & 13 \\
\hline & Anguilla bicolor bicolor & 16,700 & NC_006534 & 13 \\
\hline & Anguilla bicolor pacifica & 16,693 & NC_065035 & 13 \\
\hline \multirow{2}{*}{ Moringuidae } & Moringua microchir & 15,858 & NC_013602 & 13 \\
\hline & Moringua edwardsi & 16,841 & NC_013622 & 64 \\
\hline \multirow{2}{*}{ Chlopsidae } & Kaupichthys hyoproroides & 16,662 & NC_013607 & 64 \\
\hline & Robinsia catherinae & 16,627 & NC_013633 & 64 \\
\hline \multirow{3}{*}{ Synaphobranchidae } & Simenchelys parasitica & 16,689 & NC_013605 & 64 \\
\hline & Synaphobranchus kaupli & 16,166 & NC_005805 & 13 \\
\hline & Ilyophis brunneus & 16,682 & NC_013634 & 13 \\
\hline Heterenchelyidae & Pyhonichthys microphthalmus & 17,042 & NC_013601 & 13 \\
\hline Myrocongridae & Myroconger compressus & 16,642 & NC_013631 & 64 \\
\hline \multirow{6}{*}{ Muraenidae } & Scuticaria tigrina & 16,521 & KP874183 & 13 \\
\hline & Gymnomuroena zebra & 16,576 & NC_027240 & 13 \\
\hline & Gymnothorax formosus & 16,558 & KP874184 & 13 \\
\hline & Gymnnothorax kidako & 16,579 & NC_04417 & 13 \\
\hline & Rhinomuroena quaesita & 16,566 & NC_013610 & 13 \\
\hline & Gymnothorax minor & 16,574 & NC_038175 & Unpublished \\
\hline \multirow{3}{*}{ Derichthyidae } & Derichthys serpentinus & 17,077 & NC_013611 & 64 \\
\hline & Coloconger cadenati & 17,755 & NC_013606 & 64 \\
\hline & Nessorhamphus inglfianus & 17,782 & NC_013608 & 64 \\
\hline \multirow{4}{*}{ Nettastomatidae } & Facciolella oxyrhyncha & 17,789 & NC_013621 & 64 \\
\hline & Hoplunnis punctota & 17,828 & NC_013623 & 64 \\
\hline & Leptocephalus sp & 18,037 & NC_013615 & 64 \\
\hline & Nettastoma parviceps & 17,714 & NC_013625 & 64 \\
\hline \multirow{4}{*}{ Congridae } & Conger myriaster & 18,705 & NC_002761 & 8 \\
\hline & Conger japonicu & 17,778 & NC_027186 & 64 \\
\hline & Heteroconger hassi & 17,768 & NC_013629 & 64 \\
\hline & Paraconger notialis & 17,729 & NC_013630 & 64 \\
\hline \multirow{2}{*}{ Muraenesocidae } & Muraenesox bogio & 18,247 & NC_013614 & 64 \\
\hline & Muraenesox cinereus & 17,673 & MT571331 & This study \\
\hline \multirow{4}{*}{ Ophichthidae } & Ophichthus rotundus & 17,785 & KY081397 & 64 \\
\hline & Ophichthus brevirostris & 17,773 & MK189459 & 13 \\
\hline & Ophisurus macrorhynchos & 17,843 & NC_005802 & 13 \\
\hline & Myrichthys maculosus & 17,859 & NC_013635 & 64 \\
\hline Eurypharyngidae & Eurypharynx pelecanoides & 18,978 & NC_005299 & 63 \\
\hline Saccopharyngidae & Saccopharynx lavenbergi & 18,495 & NC_005298 & 63 \\
\hline
\end{tabular}

Table 1. List of 44 Anguilliformes species and 2 outgroups used in this paper.

a common phenomenon ${ }^{51-53}$. For genes with TAA as the stop codon, one of the most common interpretations is that produced by polyadenylation after transcription ${ }^{54}$. In the 13 PCGS, the values of COI, ATP6, COII, ND3, and ND4 of the AT-skew and GC-skew are negative, and the rest is both positive and GC-skew is negative (Table 3).

According to the codon degeneracy pattern, the amino acids serine and leucine are encoded by six synonymous codons, and the remaining amino acids are encoded by four or two codons. This result also appears in the research results of Vandana et $\mathrm{al}^{55}$. The most used amino acids are Leu (15.82\%), Ile (8.07\%) and Ala (7.96\%), the few most used amino acids are Asp (2.12\%), Arg (1.94\%) and Cys (0.84\%) (Fig. 2a). The relative synonymous 


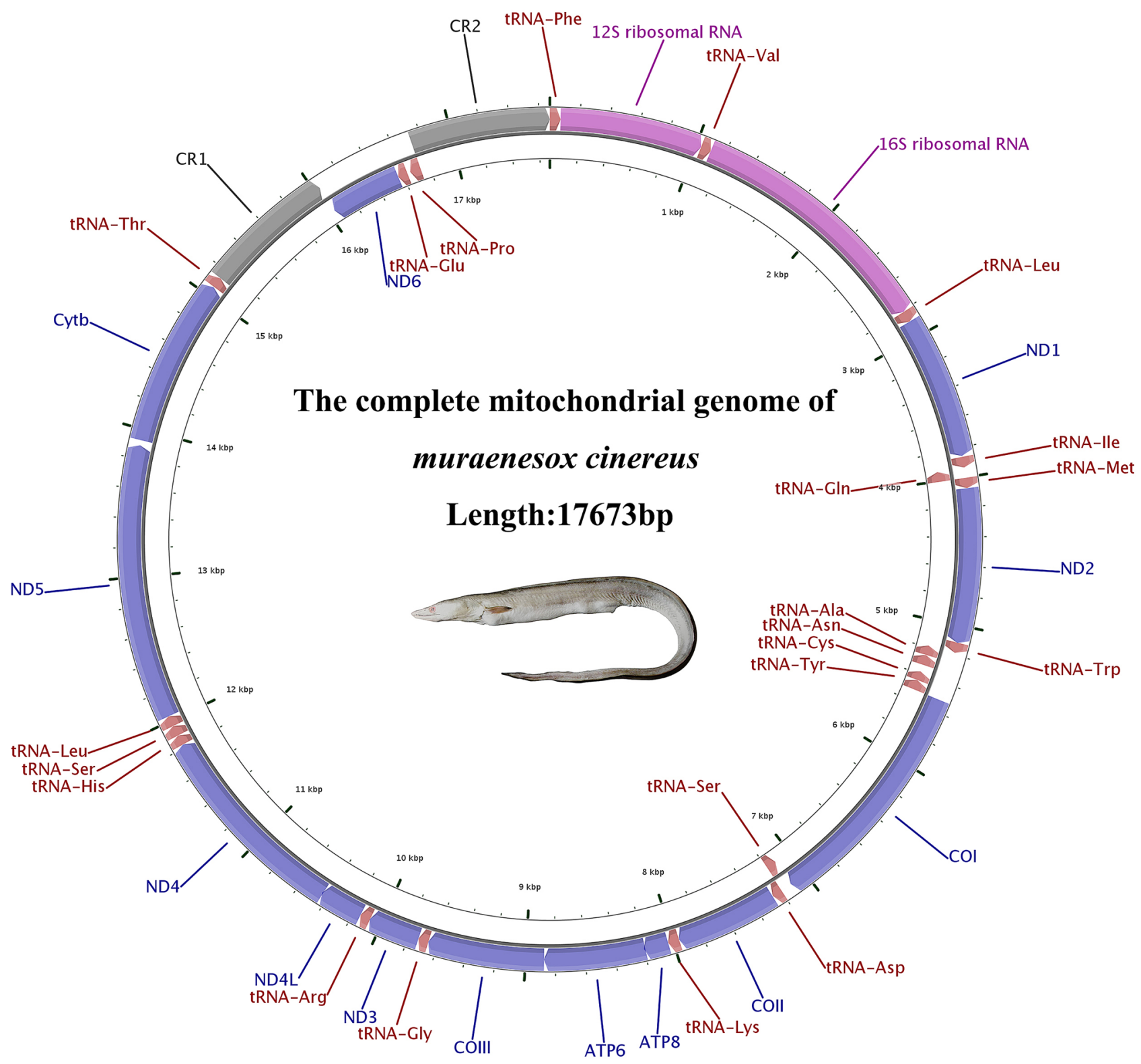

Figure 1. Muraenesox cinereus mitochondrial genome visualization ring diagram.

codon usage (RSCU) value for M. cinereus for the third position is shown in Fig. 2b. The usage of both two- and four-fold degenerate codons was biased toward the use of codons abundant in A, while there was an overall bias against $\mathrm{G}$.

Transfer RNAs, ribosomal RNAs and CR. There were also 22 tRNAs in the mitochondrial genes of $M$. cinereus, like those of other vertebrates. Of these 22 tRNAs, 14 tRNAs were encoded on the heavy chain and the remaining eight ( $t R N A-G l n, t R N A-A l a, t R N A-A s n, t R N A-C y s, t R N A-T y r$, tRNA-Ser, $t R N A-G l u$ and $t R N A-$ Pro) were encoded on the light chain (Fig. 1). Among the 22 tRNAs, except that $t R N A-S e r^{U C A}$ lacks the entire dihydrouridine arm, all other tRNAs have a typical clover structure (Fig. 3). In this case, tRNA-Ser lacks the dihydrouridine arm and is often seen in the mitochondrial of other vertebrates ${ }^{13,52}$. The length of $M$. cinereus mitochondrial tRNA is $1564 \mathrm{bp}$, and the length of 22 tRNA is between 66 and $76 \mathrm{bp}$; the base composition was $\mathrm{A}=32.0 \%, \mathrm{~T}=25.3 \%, \mathrm{C}=23.1 \%$ and $\mathrm{G}=19.6 \%$ (Tables 1,3 ). The AT and $\mathrm{GC}$ skew values of tRNA genes were 0.116 and -0.081 , respectively, which indicated that As and Cs were more abundant than Ts and Gs. The origin of light chain replication (OL) was usually located within a WANCY cluster, approximately two-thirds of the genomic distance from CR, and can fold into a stable stem ring secondary structure. Among the 22 tRNAs encoding 20 amino acids, two amino acids have two anti-codon sites, these two amino acids were Ser and Leu, and their anticodons were TGA/GCT and TAA/TAG, respectively. The small coding subunit (12S rRNA) and large coding subunit (16S rRNA) appeared on both sides with $\operatorname{trnF}$ and $\operatorname{trn} L^{(U U A)}$, which were located on the $\mathrm{H}$-chain and separated by the $\operatorname{tr} V \mathrm{~V}$ gene. The two rRNA genes are 2,668 bp in total length, and the base composition is $\mathrm{A}=35.1 \%, \mathrm{~T}=21.7 \%, \mathrm{C}=22.6 \%$, and $\mathrm{G}=20.6 \%$. The AT-skew value was positive $(0.236)$ and the $\mathrm{GC}$-skew 


\begin{tabular}{|c|c|c|c|c|c|c|c|c|}
\hline \multirow[b]{2}{*}{ Gene } & \multicolumn{2}{|c|}{ Position } & \multirow[b]{2}{*}{ Length (bp) } & \multirow[b]{2}{*}{ Amino acid } & \multirow[b]{2}{*}{ Start/Stop codon } & \multirow[b]{2}{*}{ Anticodon } & \multirow{2}{*}{$\begin{array}{l}\text { Intergenic region } \\
\text { (bp) }\end{array}$} & \multirow[b]{2}{*}{ Strand } \\
\hline & From & To & & & & & & \\
\hline tRNA-Phe (F) & 1 & 72 & 72 & & & GAA & 0 & $\mathrm{H}$ \\
\hline 12S RNA & 73 & 1034 & 962 & & & & 0 & $\mathrm{H}$ \\
\hline tRNA-Val (V) & 1035 & 1104 & 70 & & & TAC & 0 & $\mathrm{H}$ \\
\hline 16S RNA & 1105 & 2810 & 1706 & & & & 0 & $\mathrm{H}$ \\
\hline tRNA-Leu $u^{\mathrm{UUA}}\left(L_{I}\right)$ & 2811 & 2886 & 76 & & & TAA & 0 & $\mathrm{H}$ \\
\hline ND1 & 2887 & 3855 & 969 & 323 & ATG/TAA & & 0 & $\mathrm{H}$ \\
\hline tRNA-Ile (I) & 3863 & 3934 & 72 & & & GAT & 7 & $\mathrm{H}$ \\
\hline tRNA-Gln (Q) & 3935 & 4005 & 71 & & & & 0 & $\mathrm{~L}$ \\
\hline$t R N A-\operatorname{Met}(M)$ & 4005 & 4074 & 70 & & & CAT & -1 & $\mathrm{H}$ \\
\hline ND2 & 4075 & 5118 & 1044 & 348 & ATG/TAG & & 0 & $\mathrm{H}$ \\
\hline$t R N A-\operatorname{Tr} p(W)$ & 5117 & 5186 & 70 & & & TCA & -2 & $\mathrm{H}$ \\
\hline tRNA-Ala $(A)$ & 5188 & 5256 & 69 & & & TGC & 1 & $\mathrm{~L}$ \\
\hline tRNA-Asn $(N)$ & 5258 & 5330 & 73 & & & GTT & 1 & $\mathrm{~L}$ \\
\hline $\mathrm{O}_{\mathrm{L}}$ & 5331 & 5369 & 39 & & & & -7 & $\mathrm{H}$ \\
\hline tRNA-Cys $(C)$ & 5381 & 5446 & 66 & & & GCA & 7 & $\mathrm{~L}$ \\
\hline tRNA-Tyr $(Y)$ & 5447 & 5517 & 71 & & & GCA & 0 & $\mathrm{~L}$ \\
\hline $\mathrm{COI}$ & 5519 & 7121 & 1603 & 534 & GTG/TAA & & 1 & $\mathrm{H}$ \\
\hline$t R N A-\operatorname{Ser}^{\mathrm{UCA}}\left(S_{1}\right)$ & 7122 & 7192 & 71 & & & TGA & 0 & $\mathrm{~L}$ \\
\hline tRNA-Asp (D) & 7198 & 7265 & 68 & & & GTC & 5 & $\mathrm{H}$ \\
\hline COII & 7269 & 7959 & 691 & 230 & ATG/T & & 3 & $\mathrm{H}$ \\
\hline tRNA-Lys $(K)$ & 7960 & 8034 & 75 & & & TTT & 0 & $\mathrm{H}$ \\
\hline ATP8 & 8036 & 8203 & 168 & 56 & ATG/TAA & & 1 & $\mathrm{H}$ \\
\hline ATP6 & 8194 & 8877 & 684 & 228 & ATG/TAA & & -10 & $\mathrm{H}$ \\
\hline COIII & 8877 & 9662 & 786 & 262 & ATG/TAA & & -1 & $\mathrm{H}$ \\
\hline tRNA-Gly $(G)$ & 9662 & 9731 & 70 & & & TCC & -1 & $\mathrm{H}$ \\
\hline ND3 & 9732 & 10,082 & 351 & 117 & ATG/TAG & & 0 & $\mathrm{H}$ \\
\hline$t R N A-\operatorname{Arg}(R)$ & 10,081 & 10,150 & 70 & & & TCG & -2 & $\mathrm{H}$ \\
\hline ND4L & 10,151 & 10,447 & 297 & 99 & ATG/TAA & & 0 & $\mathrm{H}$ \\
\hline ND4 & 10,441 & 11,821 & 1381 & 460 & ATG/T & & -7 & $\mathrm{H}$ \\
\hline tRNA-His (H) & 11,822 & 11,890 & 69 & & & GTG & 0 & $\mathrm{H}$ \\
\hline$t R N A-\operatorname{Ser}^{\mathrm{AGC}}\left(S_{2}\right)$ & 11,891 & 11,961 & 71 & & & GCT & 0 & $\mathrm{H}$ \\
\hline tRNA-Leu ${ }^{\mathrm{CUA}}\left(L_{2}\right)$ & 11,962 & 12,033 & 72 & & & TAG & 0 & $\mathrm{H}$ \\
\hline ND5 & 12,034 & 13,890 & 1857 & 619 & ATG/TAA & & 0 & $\mathrm{H}$ \\
\hline Cyt b & 13,926 & 15,065 & 1140 & 380 & ATG/AGA & & 35 & $\mathrm{H}$ \\
\hline tRNA-Thr $(T)$ & 15,070 & 15,141 & 72 & & & TGT & 4 & $\mathrm{H}$ \\
\hline CR1 & 15,142 & 16,043 & 902 & & & & 0 & $\mathrm{H}$ \\
\hline ND6 & 16,044 & 16,559 & 516 & 172 & ATG/AGG & & 0 & $\mathrm{~L}$ \\
\hline tRNA-Glu (E) & 16,561 & 16,629 & 69 & & & TTC & 1 & $\mathrm{~L}$ \\
\hline tRNA-Pro $(P)$ & 16,653 & 16,729 & 77 & & & TGG & 23 & $\mathrm{~L}$ \\
\hline CR2 & 16,730 & 17,673 & 944 & & & & 0 & $\mathrm{H}$ \\
\hline
\end{tabular}

Table 2. Features of the mitochondrial genome of Muraenesox cinereus.

value was negative $(-0.047)$, which indicates that there were more adenine and cytosine nucleotides in rRNAs (Table 3).

The lengths of the two CRs were $902 \mathrm{bp}$ and $944 \mathrm{bp}$, respectively, and the total length was $1846 \mathrm{bp}$, of which the ratio of AT was $66.3 \%$ (Tables 1,3). The AT ratio of the CR region is higher than that of other parts of mitochondrial genes, so the $\mathrm{CR}$ region is also called the "AT-rich region", which was also common in the mitochondria of other fish. Both AT and GC skew values were 0.092 and -0.066 , indicating that the number of adenine and cytosine nucleotides was higher than that of thymine and guanine nucleotides. The palindrome sequence motifs "TACAT" and "ATGTA" related to the termination of heavy chain replication were found in both CRs, and had been reported in other study ${ }^{56}$ (Fig. 4).

Gene rearrangement. Compared with the gene arrangement in the vertebrate mitochondrial genome, the gene order in the moray mitochondrial genome obviously rearranged ${ }^{57}$ (Fig. 1). The position of the three genes (ND6, trnE and CR) in the moray M. cinereus mitochondria had changed. In general, ND6 and the bound trnE 


\begin{tabular}{|l|l|l|l|l|l|c|l|c|}
\hline & A & T & C & G & A+T\% & AT-skew & GC-skew & Length (bp) \\
\hline Mitogenome & 32.1 & 27.6 & 23.8 & 16.6 & 59.7 & 0.076 & -0.179 & 17,673 \\
\hline ND1 & 28.8 & 28.6 & 26.9 & 15.7 & 57.4 & 0.004 & -0.264 & 969 \\
\hline ND2 & 34.9 & 28.7 & 24.0 & 12.4 & 63.6 & 0.096 & -0.321 & 1044 \\
\hline COI & 26.4 & 31.1 & 24.0 & 18.5 & 57.5 & -0.082 & -0.128 & 1603 \\
\hline COII & 30.1 & 28.5 & 24.5 & 16.9 & 58.6 & 0.027 & -0.182 & 691 \\
\hline ATP8 & 35.1 & 30.4 & 25.6 & 8.9 & 65.5 & 0.073 & -0.483 & 168 \\
\hline ATP6 & 30.3 & 32.6 & 24.4 & 12.7 & 62.9 & -0.037 & -0.315 & 684 \\
\hline COIII & 28.1 & 30.7 & 23.9 & 17.3 & 58.8 & -0.043 & -0.160 & 786 \\
\hline ND3 & 28.2 & 33.3 & 24.8 & 13.7 & 61.5 & -0.083 & -0.289 & 351 \\
\hline ND4 & 31.3 & 29.8 & 23.6 & 15.4 & 61.0 & 0.025 & -0.212 & 1381 \\
\hline ND4L & 25.9 & 27.6 & 29.3 & 17.2 & 53.5 & -0.031 & -0.261 & 297 \\
\hline ND5 & 32.5 & 28.4 & 25.5 & 13.6 & 60.9 & 0.067 & -0.304 & 1857 \\
\hline Cytb & 28.7 & 27.9 & 26.4 & 17.0 & 56.6 & 0.014 & -0.216 & 1140 \\
\hline ND6 & 44.6 & 14.1 & 28.3 & 13 & 58.7 & 0.520 & -0.370 & 516 \\
\hline tRNA & 32.0 & 25.3 & 23.1 & 19.6 & 57.3 & 0.116 & -0.081 & 1564 \\
\hline rRNA & 35.1 & 21.7 & 22.6 & 20.6 & 56.7 & 0.236 & -0.047 & 2668 \\
\hline CR & 36.2 & 30.1 & 18.0 & 15.8 & 66.3 & 0.092 & -0.066 & 1846 \\
\hline
\end{tabular}

Table 3. Composition and skewness of Muraenesox cinereus mitogenome.

were located between the ND5 and Cytb genes, and only one CR region was located at the end of the mitochondrial genome. However, the position of ND6 and $\operatorname{trnE}$ in the mitochondrial genome of $M$. cinereus changed, and a CR was copied (Fig. 5). In this study, except for ND6, trnE translocation and CR repeat, the remaining gene sequence was the same as the gene sequence in the vertebrate mitochondrial genome (Fig. 5).

How did the rearrangement occur in the M. cinereus mitochondrial genome? Considering the gene rearrangement model previously described in this study, we must consider which model is best suited to explain the gene rearrangement observed in the $M$. cinereus mitochondrial genome. Recombination model was only suitable for the exchange and reversal of small fragments, and this model was relatively rare in the mitochondrial genome ${ }^{58,59}$. Therefore, this recombination model is not suitable for explaining the mitochondrial gene rearrangement of $M$. cinereus. Regarding the TDNL and DRRL models, these two models were most used in genome rearrangement, where genes were clustered with the same polarity (L- or H-chain coding) and their relative order has not changed ${ }^{27,43}$. Therefore, the two models are also not suitable to explain the phenomenon of molecular rearrangement of $M$. cinereus. This tandem duplication and random loss (TDRL) model explains well the rearrangement of genes with redundant genes. The TDRL model was due to the incomplete deletion of repeated genes leading to the existence of intergenic spacers or pseudogenes ${ }^{23,60,61}$. Therefore, in this study, the TDRL model was suggested for rearrangement events, because gene rearrangements with repeated CRs were observed in the mitochondrial genome of $M$. cinereus, as described previously in the mitochondrial genome of parthenogenetic lizards ${ }^{62}$. The evidence of the TDRL model was indicated by the presence of pseudogenes or duplicate genes and the position of the gene spacer. There are four intervals in the rearrangement region of the mitochondrial genome of moray eel, located between ND5 and Cytb, trnT and CR1, ND6 and trnE, trnE and trnP, this phenomenon provides the basis for this model (Table 2).

Based on the principle of parsimony, we made assumptions about the region of the moray mitochondrial genome rearrangement, assuming the intermediate steps of gene rearrangement as follows. First, after the normal mitochondrial gene block (ND6-trnE-Cyt b-trnT-trnP-CR) is completely replicated, a gene block (ND6-trnE-Cyt b-trnT-trnP-CR-ND6-trnE-Cyt b-trnT-trnP-CR) (Fig. 5a,b). Then, after consecutive copies, other genes (ND6, $\operatorname{trn} E, C y t b, \operatorname{trn} T$ and $\operatorname{trn} P$ ) were randomly lost in addition to CR. After the copied genes are randomly lost, the positions of the two genes in the red dotted box and the two genes in the cyan dotted box in Fig. $5 \mathrm{c}$ are swapped, and then inserted after the two genes in the red dotted box CR2. Therefore, after such copying and random loss, both CRs are preserved. We speculate that both CRs retain their original functions. In other animal mitochondrial genomes, similar hypotheses have been proposed ${ }^{47}$.

Phylogenetic analysis. To further study the evolutionary status of M. cinereus in the Anguillaridae, we selected 14 closely related families and two outgroups (Saccopharynx lavenbergi and Eurypharynx pelecanoides ${ }^{63}$ ) to construct evolutionary trees (BI and ML) to analyze phylogenetic relationships. After removing highly differentiated regions, a phylogenetic tree was constructed with 10,987 bp sequence. The results show that the topological structure of the ML tree and the BI tree are basically the same. Therefore, we merge two trees together to form a tree. In addition, the BI tree has a higher support value than the ML tree (Fig. 6). Both trees clearly show that $M$. cinereus and $M$. bagio were the closest in relationship, and that these two species form the Muranesocide branches (BI posterior probabilities $[\mathrm{PP}]=1$; ML bootstrap $[\mathrm{BP}]=100$ ). The mitochondrial genome structures of $M$. cinereus and M. bagio were very similar. However, there was no other gene between $t R N A-T h r$ and ND6 gene in $M$. bagio $^{64}$ mitochondrial genome, but CR1 gene existed between $t R N A-T h r$ and ND6 gene in $M$. cinereus mitochondrial genome. In the M. bagio mitochondrial genome, ND6 combined with $t R N A-G l u$ rearranged and 

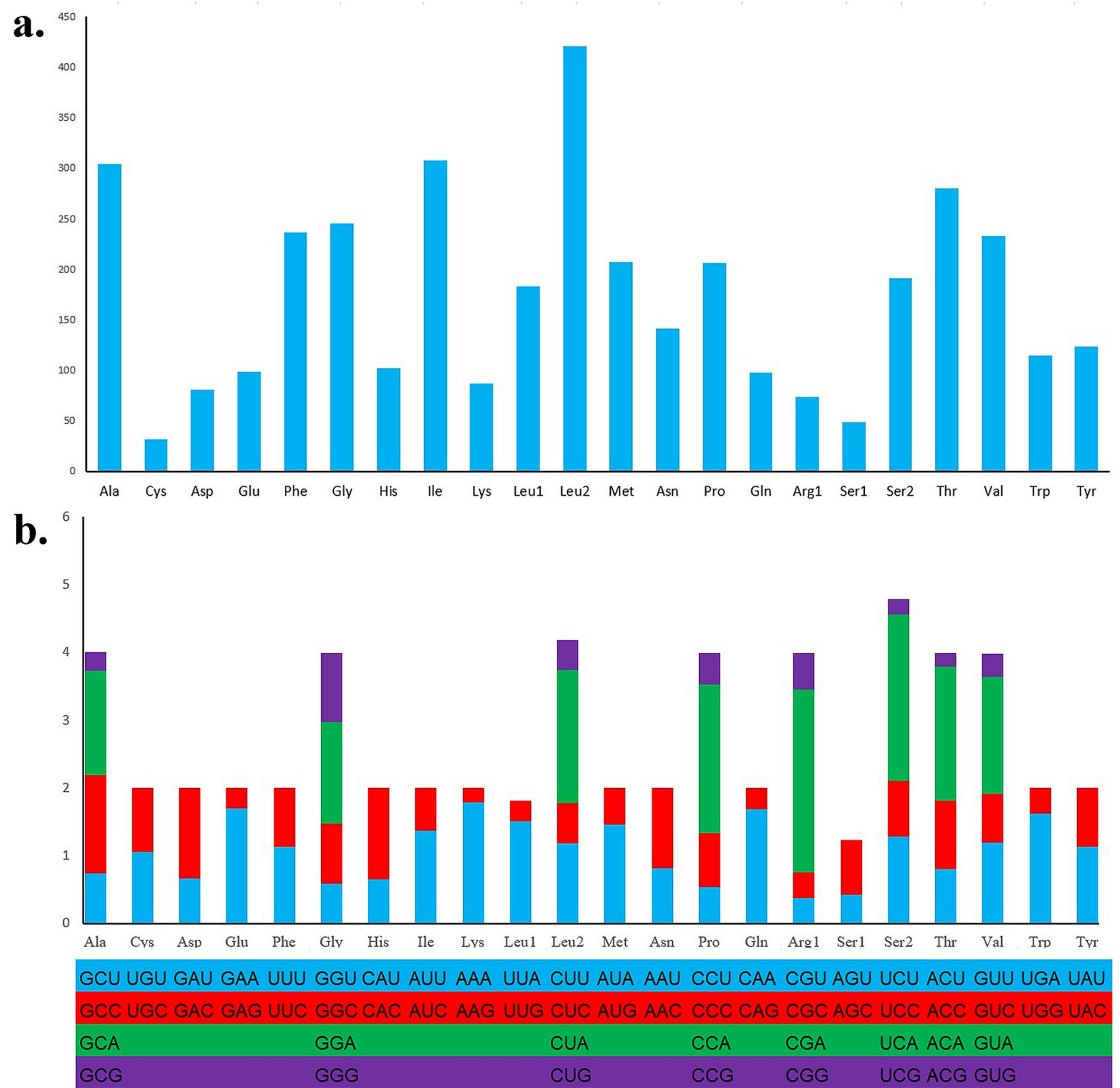

Figure 2. Amino acid composition (a) and Relative synonymous codon usage (b) in Muraenesox cinereus mitogenome.

transferred between the $t R N A-T h r$ and $t R N A-P r o$ genes. However, in the mitochondria of M. cinereus, not only ND6 and tRNA-Glu were rearranged, but also the CR gene was rearranged. Inoue et al.'s ${ }^{64}$ complete mitochondrial data studies and Santini et al.s ${ }^{7}$ tandem dataset (mitochondrial and nuclear genes) studies also support Congridae's non-singularity ${ }^{9,65}$. Regarding the unity of Nettastomatidae, the ML tree showed that all Nettastomatidae species were grouped into a clade, and supported the origin of single lines. However, the BI tree divided Nettastomatidae into two clades, indicating that Nettastomatidae was non-singleton, which was consistent with the results of Inoue ${ }^{64}$ and $\mathrm{Lu}$ et $\mathrm{al}^{13}$. Our results indicated that both Derichthyidae and Chlopsidae were monophyletic, but Santini et al.'s ${ }^{7}$ results were contrary to ours. For the main relationship between the Anguilliformes lineage and different families, our results were basically consistent with previous molecular studies ${ }^{66,67}$.

In our research, it was found that Chlopsoidei, Muraenoidei and Anguilloidei all had typical vertebrate mitochondrial genome sequences, but Congroidei had two different patterns of gene arrangement: (1) with typical vertebrate gene order (Nemichthyidae, Serrivomeridae and Synaphobranchidae) (2) with gene rearrangement (Derichthyidae, Nettastomatidae, Congridae, Muraenesocidae and Ophichthidae). The four families (Ophichthidae, Derichthyidae, Muraenesocidae and Nettastomatidae) studied by Inoue et al. ${ }^{8}$ also had mitochondrial genes lacking ND6 and trnE, which were also clustered, which was also consistent with our results. In this study, we found an interesting phenomenon. The five families with gene rearrangement at the bottom formed a 

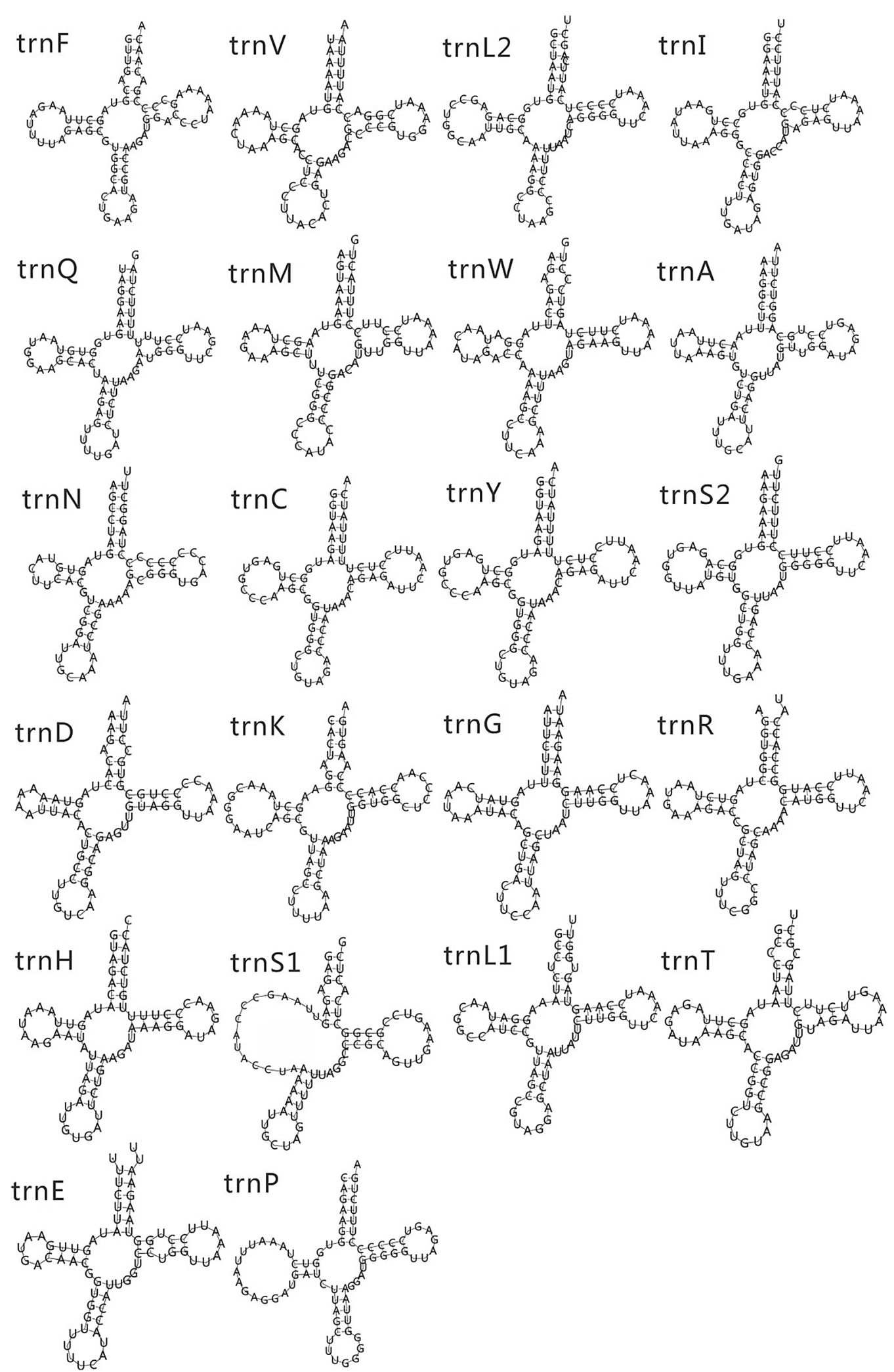

Figure 3. The secondary structure of tRNA in the mitochondrial genome of Muraenesox cinereus.

branch, and those without gene rearrangement formed a separate branch at the top of the tree (The cyan ellipse in Fig. 6 indicates that no gene rearrangement had occurred; the red ellipse indicated that gene rearrangement 


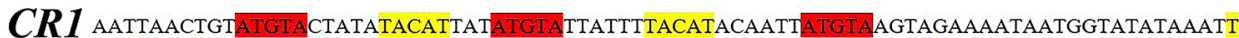
ACATAATTAATGTAAATAATAGTGTTATGAAACATTTTAAGTGTTTGTGACATTTTAATTAATATACATATAAAATCTCTCGACCA TTTATGTTTGGTAAATAATTCTAAGACAGACATAAACATAAAAGTTGAGTACTAACACAAAATTATACAAACAAGGAAAAATTG AAAACTCCAATAATTAATTGTCGCGAGCAAAGTTTCTATGAATAAACAACAGTTGATTTCCTACAAACAATAATGCGCAGTAAGA GACCACCAACCAGCTTTAATCAGAGTGAATACGTTTATTGAAAGGTCAGGGACAAAAATTGTGGGGGTAGTACTGGGTGAACTA TTCCTGGCATCTGGTTCCTATTTCAGGGCCATAAAATTAAAACCCCCCAGTAGGTTGCACTGTATCCGGCATTTGATTAATGGTGT AACCCATACGACTCGTTACCCACCAAGCCGGGCGTTAACCAAATGGCATTTGGTTCTTTTTTTTAGGTTTCCTTTCACTCCACATG TGGGACTTCTGCCGTAAGGCTAATTGTGAAGGTGGAACTCAATGAGATGTATTCATGTAATTATGATGAATGATAAAAAGACATA ACCTAAGAGTTGCATTAAACTATATCAGGTGCATACACTTGTATTGCCAAGATCAGATACTACTGTTATTTCCCCCCCTTGAACGA AAATTTTAGGGTACCCCCCCCTACCCCCCCCTAAAAAGACCATGTCTAATTAGAGTTTAAAGTCCGGTCAAACCAATAATTAAAT AAGTTAAAGTTTACCAATATTATTAATCGCCTGAGCCCCAACCATTACCAAAAAG

$\boldsymbol{C} \boldsymbol{R} 2$ ACTAAAATAACAAAGTAATTAAAGATATATTATAAAAATTACAAAACCACCTATGTACTATATACATTATATGTATTAT TTTACATACAATTATGTAAGTAGAAAATAATGGTATATAAATTACATAATTAITGTAAATAATAGTGTTATGAAACATTTTAAGT GTTTGTGACATTTTAATTAATATACATATAAAATCTCTCGACCATTTATGTTTGGTAAATAATTCTAAGACAGACATAAACATAAA AGTTGAGTACTAACACAAAATTATACAAACAAGGAAAAATTGAAAACTCCAATAATTAATTGTCGCGAGCAAAGTTTCTATGAA TAAACAACAGTTGATTTCCTACAAACAATAATGCGCAGTAAGAGACCACCAACCAGCTTTAATCAGAGTGAATACGTTTATTGAA AGGTCAGGGACAAAAATTGTGGGGGTAGTACTGGGTGAACTATTCCTGGCATCTGGTTCCTATTTCAGGGCCATAAAATTAAAAC CCCCCAGTAGGTTGCACTGTATCCGGCATTTGATTAATGGTGTAACCCATACGACTCGTTACCCACCAAGCCGGGCGTTAACCAA ATGGCATTTGGTTCTTTTTTTTAGGTTTCCTTTCACTCCACATGTGGGACTTCTGCCGTAAGGCTAATTGTGAAGGTGGAACTCAA TGAGATGTATTCATGTAATTATGATGAATGATAAAAAGACATAACCTAAGAGTTGCATTAAACTATATCAGGTGCATACACTTGT ATTGCCAAGATCAGATACTACTGTTATTTCCCCCCCTTGAACGAAAATTTTAGGGTACCCCCCCCTACCCCCCCCTAAAAAGACC ATGTCTAATTAGAGTTTAAAGTCCGGTCAAACCAATAATTAAATAAGTTAAAGTTTACCAATATTATTAATCGCCTGAGCCCCAA CCATTACCAAAAAG

Figure 4. Compositional features of the control region of the Muraenesox cinereus mitochondrial genome. Palindromic motif sequence "TACAT' and 'ATGTA' are marked in yellow and green respectively.

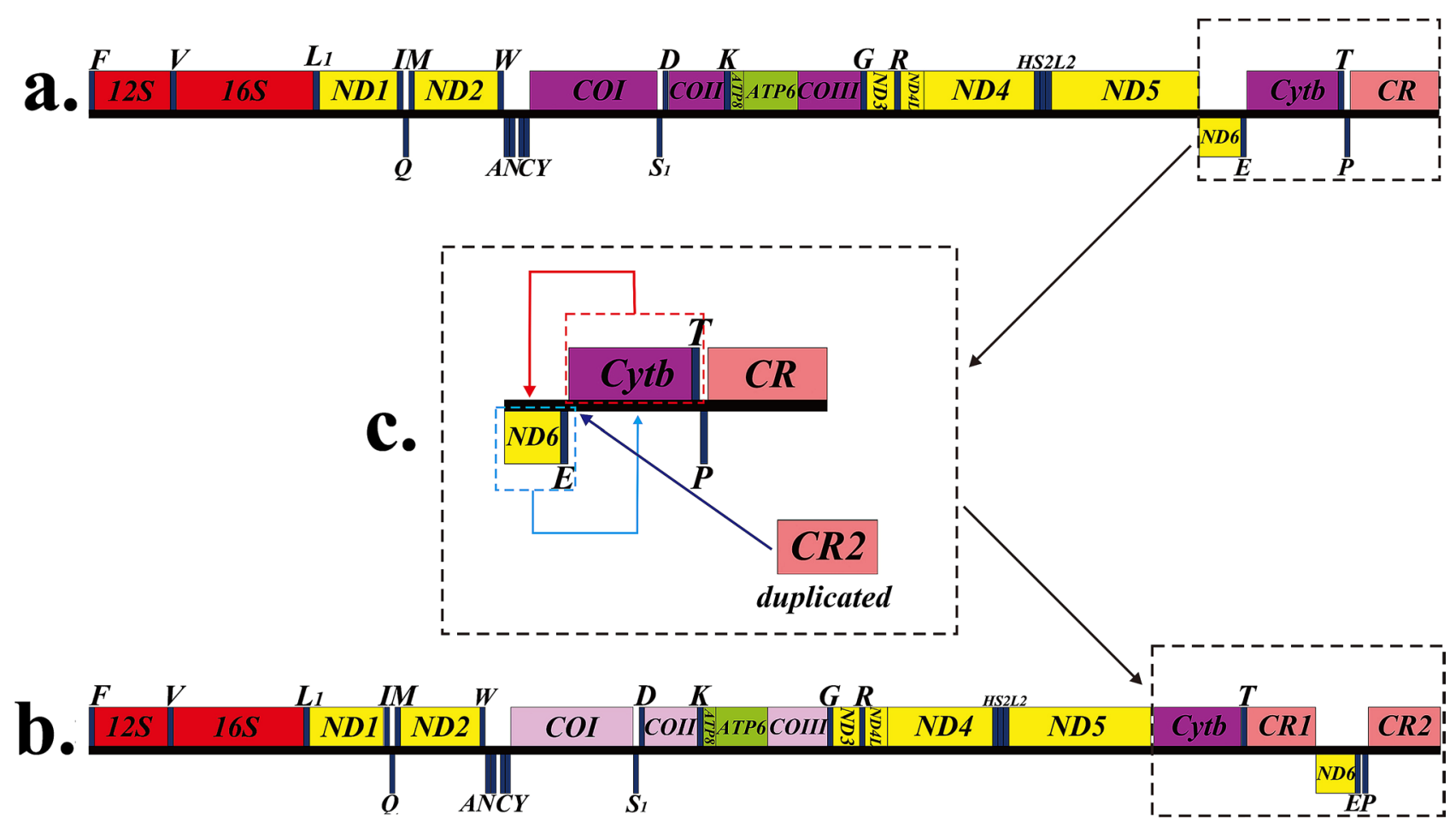

Figure 5. Analysis of Muraenesox cinereus mitochondrial gene rearrangement.

had occurred). These results indicate that the origin of eels is a diverse evolution. If the new gene sequence originates from a single ancestral species in the Congroidei suborder, then this pattern of presence/absence may be a good phylogenetic marker for identifying monoline populations as Kumazawa and Nishida ${ }^{68}$ and Macey et $\mathrm{al}^{18}$ suggested, they had a higher vertebrate relationship. Therefore, more advanced methods can be considered to classify the controversial Anguilliformes species. There are still some phylogenetic mismatches based on morphological and molecular data, so more eel mitochondrial genomes should be sequenced to support this hypothesis in future research.

\section{Conclusion}

With the advancement of genetics research, many people believe that the richness of molecular information is superior to morphological data, and molecular analysis has become the most commonly used methods in the study of biological system development. Therefore, in this study, we sequenced and assembled the complete 


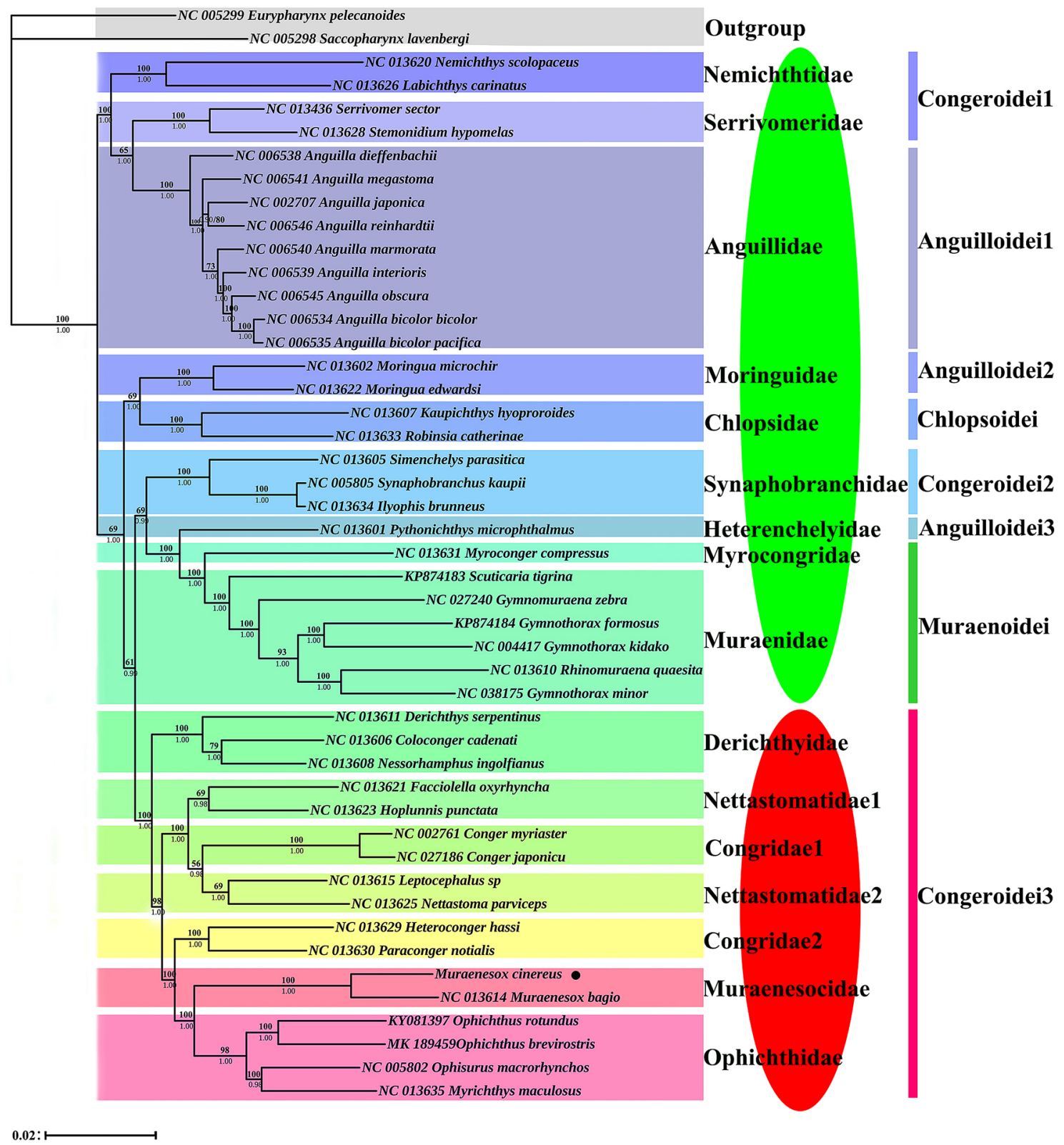

Figure 6. Phylogenetic analysis based on the nucleotide sequences of the 12 PCGs in the mitogenome. The numbers beside the nodes are posterior probabilities (BI, bottom) and bootstrap (ML, top). Red ellipse: gene rearrangement occurs; cyan ellipse: no gene rearrangement occurs.

mitochondrial gene of $M$. cinereus and described its characteristics, which contains 37 genes and two control regions. After comparing with the typical vertebrate mitochondrial genes, we found that $M$. cinereus mitochondrial gene rearrangement obviously occurred, the rearrangement part of the gene ND6 and trnE were transferred between $\operatorname{trnT}$ and $\operatorname{trn} P$, accompanied by CR repeat. The most suitable model to explain this rearrangement phenomenon is the duplication-random loss model. The two phylogenetic trees (BI and ML) created using the mitochondrial genomes from 46 Anguilliformes were basically consistent with previous molecular studies on the interrelationships between the main Anguilliform lineages and different families, although some of these families were slightly related different. Both phylogenetic trees strongly support the non-monophyly of Congridae, providing a basis for the more advanced classification of Anguilliformes. In addition, our research results provide a theoretical basis for in-depth understanding of the mechanism and evolution of $M$. cinereus gene rearrangement and phylogenetic studies of eel. 
Materials and methods

Sample collection permit and experimental approval. All procedures in this study were performed under the guidelines of the Regulations for the Administration of Laboratory Animals (Decree No. 2 of the State Science and Technology Commission of the People's Republic of China, November 14, 1988), and were approved by the Animal Ethics Committee of Zhejiang Ocean University (Zhoushan, China).

Fish sample, DNA extraction, PCR amplification and sequencing. Individual $M$. cinereus specimens were collected by a commercial trawl fishing method in Zhoushan City, Zhejiang Province, China $\left(30^{\circ} 40^{\prime}\right.$ $30^{\prime \prime} \mathrm{N}, 121^{\circ} 20^{\prime} 28^{\prime \prime} \mathrm{E}$ ) and immediately preserved with $95 \%$ ethanol. Total genomic DNA was extracted using the SQ tissue DNA kit (OMEGA) according to the manufacturer's protocol. After extraction, the DNA was stored in $-4{ }^{\circ} \mathrm{C}$ refrigerator. The polymerase chain reaction (PCR) primers used in this experiment designed 10 pairs of primers for the amplification of the complete mitochondrial genome of $M$. cinereus based on the complete mitochondria published by the predecessors ${ }^{13,69,70}$ (Table S1). The PCR was carried out in a $25 \mu \mathrm{l}$ reaction volume containing $2.0 \mathrm{mM} \mathrm{MgCl}_{2}, 0.4 \mathrm{mM}$ of each dNTP, $0.5 \mu \mathrm{M}$ of each primer, $1.0 \mathrm{U}$ of Taq polymerase (Takara, China), $2.5 \mu \mathrm{l}$ of $10 \times$ Taq buffer, and approximately $50 \mathrm{ng}$ of DNA template. Using the following cycling conditions: (1) initial activation step for $5 \mathrm{~min}$ at $95^{\circ} \mathrm{C}$; (2) 35 cycles of denaturation at $95^{\circ} \mathrm{C}$ for $30 \mathrm{~s}$, annealing at $52{ }^{\circ} \mathrm{C}$ (as the case may be) for $30 \mathrm{~s}$ and extension at $72{ }^{\circ} \mathrm{C}$ for $30 \mathrm{~s}$; and (3) a final extension of $5 \mathrm{~min}$ at $72{ }^{\circ} \mathrm{C}$. The sequences were determined using an ABI genetic analyzer (Applied Biosystems, China).

Sequence assembly, annotation and analysis. The obtained sequence fragment was passed through CodonCode Aligner 9.0.1 (CodonCode Corporation, Dedham, MA) was assembled into a complete mitochondrial genome. The assembled mitochondrial genome is annotated by Sequin (version 15.10, http://www.ncbi. nlm.nih.gov/Sequin/). The boundaries of protein coding and ribosomal RNA genes were determined by NCBIBLAST (http://blast.ncbi.nlm.nih.gov). The tRNA genes were verified using MITOS WebServer (http://mitos 2.bioinf.uni-leipzig.de/index.py) using the default setting ${ }^{49}$. Composition skew values were calculated according to the following formulas ${ }^{71}$ : AT skew $=(A-T) /(A+T)$; $G C$ skew $=(G-C) /(G+C)$. The base composition and relative synonymous codon usage (RSCU) were obtained using MEGA $\mathrm{X}^{72}$. The mitochondrial gene map of cinereus was generated online by using $\mathrm{CGView}^{73}$.

Phylogenetic analyses. Download 46 complete Anguilliformes mitochondrial genomes from GenBank (https://www.ncbi.nlm.nih.gov/genbank/) for phylogenetic studies (Table 1). Saccopharyngiformes was considered to be an intimately related species to Anguilliformes ${ }^{13,74}$; therefore, we selected two species of Neocyema erythrosoma and Saccopharynx lavenbergi in Saccopharyngiformes as the outgroup in this study. The 12PCGs sequences used for phylogenetic analysis were extracted from DAMBE version 7.2.3 ${ }^{75}$. The 13 PCGs used did not include ND6 and were not used because of their heterogeneous base composition and consistent poor phylogenetic performance ${ }^{33,76}$. Sequences were aligned with default parameters using Clustal X $2.0^{77}$, and manually checked using BioEdit ${ }^{78}$. Use software Gblock ${ }^{79}$ to eliminate ambiguous sequences. Substitution vs. the Tamura$\mathrm{Nei}$ (TN93) genetic distance in pairwise comparisons was used to test for substitution saturation using DMABE version 7.2.3 $3^{75}$ The third codon position shows significant saturation (Fig. S1), so it is only defined as purine and pyrimidine. Based on Bayesian inference (BI) and maximum likelihood (ML) two methods, using PhyML ${ }^{80}$ and MrBayes 3.2. $6^{81}$ software for phylogenetic analyses. Based on the Akaike information criteria (AIC), parallel uses Modeltest $3.7^{82}$ of 56 models for ML analysis, and MrModeltest $2.2^{83}$ of 24 models for BI analysis to determine the best evolutionary model and points out that GTR $+\mathrm{G}+\mathrm{I}$ was the analysis dataset of best-fit alternative models. Perform Bootstrap analysis (1,000 repetitions) to assess the relative level of support for ML analysis ${ }^{84,85}$. Use "Lset" and "Prset" for Bayesian phylogenetic analysis and allow the program to converge to the best estimate of model parameters. Other parameter settings are as follows: each Markov chain starts from a random tree, runs for 2 million generations, and samples a tree every 100 generations (a total of 20,000 trees are sampled) to ensure the independence of the samples. In order to improve the mixing ability of the Markov chain, the Metropolis coupling Markov chain Monte Carlo (MCMCMC) method was used, and three heating chains (temperature $=0.5$ ) and one cold chain were operated simultaneously. To guarantee the stationarity had been reached, the average standard deviation of split frequencies was set below 0.01 . The phylogenetic tree was viewed in FigTree v1.4.0.

Ethical standards. Ethics Committee approval was obtained from the Institutional Ethics Committee of Zhejiang Ocean University to the commencement of the study.

Received: 17 June 2020; Accepted: 30 December 2020

Published online: 28 January 2021

\section{References}

1. Mehta, R. S. Ecomorphology of the moray bite: Relationship between dietary extremes and morphological diversity. Physiol. Biochem. Zool. 82, 90-103 (2009).

2. Mehta, R. S. \& Wainwright, P. C. Raptorial jaws in the throat help moray eels swallow large prey. Nature 449, 79-82 (2007).

3. Robins, C. R. The phylogenetic relationships of the anguilliform fishes. Fishes Western N. Atl. 1, 9-23 (1989).

4. Greenwood, P. H. Notes on the anatomy and classification of elopomorph fishes. Bull. Mus. Comp. Zool. 32, 65-102 (1977). 
5. Nelson, G. J. Relationships of clupeomorphs, with remarks on the structure of the lower jaw in fishes. Interrelat. Fishes 333-349 (1973).

6. Inoue, J. G. et al. Deep-ocean origin of the freshwater eels. Biol. Let. 6, 363-366. https://doi.org/10.1098/rsbl.2009.0989 (2010).

7. Santini, F. et al. A multi-locus molecular timescale for the origin and diversification of eels (Order: Anguilliformes). Mol. Phylogenet. Evol. 69, 884-894. https://doi.org/10.1016/j.ympev.2013.06.016 (2013).

8. Inoue, J. G., Miya, M., Tsukamoto, K. \& Nishida, M. Complete Mitochondrial DNA Sequence of Conger myriaster (Teleostei: Anguilliformes): Novel gene order for vertebrate mitochondrial genomes and the phylogenetic implications for Anguilliform Families. J. Mol. Evol. 52, 311-320 (2001).

9. Tang, K. L. \& Fielitz, C. Phylogeny of moray eels (Anguilliformes: Muraenidae), with a revised classification of true eels (Teleostei: Elopomorpha: Anguilliformes). Mitochondrial DNA. 24, 55-66 (2013).

10. Russell, B. \& Houston, W. Offshore fishes of the Arafura Sea. Beagle Rec. Mus. Art Galleries Northern Territory 6, 69-84 (1989).

11. Chen, D., Ye, Y., Chen, J., Zhan, P. \& Lou, Y. Molecular nutritional characteristics of vinasse pike eel (Muraenesox cinereus) during pickling. Food Chem. 224, 359-364. https://doi. org/10.1016/j.foodchem.2016.12.089 (2017).

12. Boore, J. L. Animal mitochondrial genomes. Nucleic Acids Res. 27, 1767-1780 (1999).

13. Lu, Z. Z. et al. Complete mitochondrial genome of Ophichthus brevicaudatus reveals novel gene order and phylogenetic relationships of Anguilliformes. Int. J. Biol. Macromol. 135, 609-618. https://doi.org/10.1016/j.ijbiomac.2019.05.139 (2019).

14. Bibb, M., Etten, R., Wright, C., Walberg, M. \& Clayton, D. Sequence and gene organization of mouse mitochondrial DNA. Cell 26, 167-180. https://doi.org/10.1016/0092-8674(81)90300-7 (1981).

15. Anderson, S. B. et al. Sequence and organization of the human mitochondrial genome. Nature 290, 457-465. https://doi. org $/ 10.1038 / 290457 \mathrm{a} 0$ (1981).

16. Roe, B. A., Ma, D. P., Wilson, R. K. \& Wong, F. H. The complete nucleotide sequence of the Xenopus laevis mitochondrial genome. J. Biol. Chem. 260, 9759-9774 (1985).

17. Brown, W., George, M. J. \& Wilson, A. C. Rapid evolution of animal mitochondrial DNA. Proc. Natl. Acad. Sci. USA 76, 1967-1971. https://doi.org/10.1073/pnas.76.4.1967 (1979).

18. Macey, J. R., Larson, A., Ananjeva, N. B., Fang, Z. \& Papenfuss, T. J. Two novel gene orders and the role of light-strand replication in rearrangement of the vertebrate mitochondrial genome. Mol. Biol. Evol. 14, 91-104. https://doi.org/10.1093/oxfordjournals. molbev.a025706 (1997).

19. Zhang, J. Y., Zhang, L. P., Yu, D. N., Storey, K. B. \& Zheng, R. Q. Complete mitochondrial genomes of Nanorana taihangnica and N. yunnanensis (Anura: Dicroglossidae) with novel gene arrangements and phylogenetic relationship of Dicroglossidae. BMC Evol. Biol. 18, 1-13 (2018)

20. Yan, J., Li, H. \& Zhou, K. Evolution of the mitochondrial genome in snakes: Gene rearrangements and phylogenetic relationships. BMC Genom. 9, 569. https://doi.org/10.1186/1471-2164-9-569 (2008).

21. Liu, J., Yu, J., Zhou, M. \& Yang, J. Complete mitochondrial genome of Japalura flaviceps: Deep insights into the phylogeny and gene rearrangements of Agamidae species. Int. J. Biol. Macromol. 125, 423-431. https://doi.org/10.1016/j.ijbiomac.2018.12.068 (2019).

22. Verkuil, Y. I., Piersma, T. \& Baker, A. J. A novel mitochondrial gene order in shorebirds (Scolopacidae, Charadriiformes). Mol. Phylogenet. Evol. 57, 411-416. https://doi.org/10.1016/j.ympev.2010.06.010 (2010).

23. Eberhard, J. R. \& Wright, T. F. Rearrangement and evolution of mitochondrial genomes in parrots. Mol. Phylogenet. Evol. 94, 34-46 (2015).

24. Pääbo, S., Thomas, W. K., Whitfield, K. M., Kumazawa, Y. \& Wilson, A. C. Rearrangements of mitochondrial transfer RNA genes in marsupials. J. Mol. Evol. 33, 426-430. https://doi.org/10.1007/bf02103134 (1991).

25. Gong, L., Shi, W., Yang, M., Li, D. \& Kong, X. Novel gene arrangement in the mitochondrial genome of Bothus myriaster(Pleuronectiformes: Bothidae): Evidence for the dimer-mitogenome and non-random loss model. Mitochondrial DNA Part A. 27, 3089-3092 (2015).

26. Miya, M. N. Organization of the Mitochondrial Genome of a Deep-Sea Fish, Gonostoma gracile (Teleostei: Stomiiformes): First example of transfer RNA gene rearrangements in Bony Fishes. Mar. Biotechnol. 1, 416-0426 (1999).

27. Shi, W., Miao, X. G. \& Kong, X. Y. A novel model of double replications and random loss accounts for rearrangements in the Mitogenome of Sssamariscus latus (Teleostei: Pleuronectiformes). BMC Genom. 15, 352 (2014).

28. Kong, X. et al. A novel rearrangement in the mitochondrial genome of tongue sole, Cynoglossus semilaevis: Control region translocation and a tRNA gene inversion. Genome. 52, 975-984. https://doi.org/10.1139/g09-069 (2009).

29. Gong, L., Shi, W., Si, L. Z. \& Kong, X. Y. Rearrangement of mitochondrial genome in fishes. Zool. Res. 34, 666-673 (2013).

30. Inoue, J. G., Masaki, M., Katsumi, T. \& Mutsumi, N. evolution of the deep-sea gulper eel mitochondrial genomes: Large-scale gene rearrangements originated within the eels. Mol. Biol. Evol. 20, 1917-1924 (2003).

31. Ishikawa, S., Kimura, Y., Tokai, T., Tsukamoto, K. \& Nishida, M. Gene rearrangement around the control region in the mitochondrial genome of conger myriaster. Fish. Sci. 66, 1186-1188 (2002).

32. Miya, M., Kawaguchi, A. \& Nishida, M. Mitogenomic exploration of higher teleostean phylogenies: A case study for moderatescale evolutionary genomics with 38 newly determined complete mitochondrial DNA sequences. Mol. Biol. Evol. 18, 1993-2009 (2001).

33. Miya, M. T. et al. Major patterns of higher teleostean phylogenies: A new perspective based on 100 complete mitochondrial DNA sequences. Mol. Phylogenet. Evol. 26, 121-138 (2003).

34. Poulton, J. et al. Families of mtDNA re-arrangements can be detected in patients with mtDNA deletions: Duplications may be a transient intermediate form. Hum. Mol. Genet. 2, 23-30 (1993).

35. Lunt, D. H. \& Hyman, B. C. Animal mitochondrial DNA recombination. Nature 387, 247 (1997),

36. Ladoukakis, E. D. \& Zouros, E. Recombination in animal mitochondrial DNA: Evidence from published sequences. Mol. Biol. Evol. 18, 2127-2131 (2001)

37. Sammler, S., Bleidorn, C. \& Tiedemann, R. Full mitochondrial genome sequences of two endemic Philippine hornbill species (Aves: Bucerotidae) provide evidence for pervasive mitochondrial DNA recombination. BMC Genom. 12, 35. https://doi. org/10.1186/1471-2164-12-35 (2011).

38. Atsushi, K. et al. Phylogeny, recombination, and mechanisms of stepwise mitochondrial genome reorganization in mantellid frogs from madagascar. Mol. Biol. Evol. 5, 874-891 (2008).

39. Arndt, A. \& Smith, M. J. Mitochondrial gene rearrangement in the sea cucumber genus Cucumaria. Mol. Biol. Evol. 8, 1009-1016 (1998).

40. Moritz, C., Dowling, T. E. \& Brown, W. M. Evolution of animal mitochondrial DNA: Relevance for population biology and systematics. Annu. Rev. Ecol. Syst. 18, 269-292 (1987).

41. Erin, E. S. et al. Multiple independent origins of mitochondrial control region duplications in the order Psittaciformes. Mol. Phylogenet. Evol. 64, 342-356. https://doi.org/10.1016/j.ympev.2012.04.009 (2012).

42. Mauro, D. S., Gower, D. J., Rafael, Z. \& Mark, W. A hotspot of gene order rearrangement by tandem duplication and random loss in the vertebrate mitochondrial genome. Mol. Biol. Evol. 23, 227-234 (2006).

43. Lavrov, D. V., Boore, J. L. \& Brown, W. M. Complete mtDNA sequences of two millipedes suggest a new model for mitochondrial gene rearrangements: Duplication and nonrandom loss. Mol. Biol. Evol. 19, 163-169 (2002).

44. Smith, M. J., Arndt, A., Gorski, S. \& Fajber, E. The phylogeny of echinoderm classes based on mitochondrial gene arrangements. J. Mol. Evol. 36, 545-554 (1993). 
45. Schierup, M. H. \& Hein, J. Consequences of recombination on traditional phylogenetic analysis. Genetics 156, 879-891 (2000).

46. Zhi, J. J. et al. Comparative mitochondrial genomics of snakes: Extraordinary substitution rate dynamics and functionality of the duplicate control region. BMC Evol. Biol. 7, 123. https://doi.org/10.1186/1471-2148-7-123 (2007).

47. Shi, W., Dong, X. L., Wang, Z. M., Miao, X. G. \& Kong, X. Y. Complete mitogenome sequences of four flatfishes (Pleuronectiformes) reveal a novel gene arrangement of L-strand coding genes. BMC Evol. Biol. 13, 173 (2013).

48. Kumazawa, Y., Ota, H., Nishida, M. \& Ozawa, T. The complete nucleotide sequence of a snake (Dinodon semicarinatus) mitochondrial genome with two identical control regions. Genetics 150, 313-329 (1998).

49. Liu, Y. et al. Mitochondrial genome of the yellow catfish Pelteobagrus fulvidraco and insights into Bagridae phylogenetics. Genomics 111, 1258-1265. https://doi.org/10.1016/j.ygeno.2018.08.005 (2019).

50. Gong, L., Lü, Z. M., Guo, B. Y., Ye, Y. Y. \& Liu, L. Q. Characterization of the complete mitochondrial genome of the tidewater goby, Eucyclogobius newberryi (Gobiiformes; Gobiidae; Gobionellinae) and its phylogenetic implications. Conserv. Genet. Resour. 10, 93-97 (2017).

51. Lin, J. P. et al. The first complete mitochondrial genome of the sand dollar Sinaechinocyamus mai (Echinoidea: Clypeasteroida). Genomics 112, 1686-1693. https://doi.org/10.1016/j.ygeno.2019.10.007 (2020).

52. Prabhu, V. R. et al. Characterization of the complete mitochondrial genome of Barilius malabaricus and its phylogenetic implications. Genomics 112, 2154-2163. https://doi.org/10.1016/j.ygeno.2019.12.009 (2020).

53. Xu, T. J., Cheng, Y. Z., Sun, Y. N., Shi, G. \& Wang, R. X. The complete mitochondrial genome of bighead croaker, Collichthys niveatus (Perciformes, Sciaenidae): Structure of control region and phylogenetic considerations. Mol. Biol. Rep. 38, 4673-4685. https://doi. org/10.1007/s11033-010-0602-4 (2011).

54. Ojala, D., Montoya, J. \& Attardi, G. tRNA punctuation model of RNA processing in human mitochondria. Nature 290, 470-474. https://doi.org/10.1038/290470a0 (1981).

55. Vandana, R. P. et al. Characterization of the complete mitochondrial genome of Barilius malabaricus and its phylogenetic implications. Genomics 112, 2154-2163 (2019).

56. Wang, X., Wang, J., He, S. \& Mayden, R. L. The complete mitochondrial genome of the Chinese hook snout carp Opsariichthys bidens (Actinopterygii: Cypriniformes) and an alternative pattern of mitogenomic evolution in vertebrate. Gene 399, 0-19 (2007).

57. Gong, L., Liu, B., Lü, Z. M. \& Liu, L. Q. Characterization of the complete mitochondrial genome of Wuhaniligobius polylepis (Gobiiformes: Gobiidae) and phylogenetic studies of Gobiiformes. Mitochondrial DNA Part B 3, 1117-1119. https://doi.org/10.1080/23802 359.2018.1519380 (2018).

58. Dowton, M. \& Campbell, N. J. H. Intramitochondrial recombination-is it why some mitochondrial genes sleep around?. Trends Ecol. Evol. 16, 269-271 (2001).

59. Kong, X. D. et al. A novel rearrangement in the mitochondrial genome of tongue sole, Cynoglossus semilaevis: Control region translocation and a tRNA gene inversion. Genome 52, 975-984. https://doi.org/10.1139/g09-069 (2009).

60. Shi, W., Gong, L., Wang, S. Y., Miao, X. G. \& Kong, X. Y. Tandem duplication and random loss for mitogenome rearrangement in symphurus (Teleost: Pleuronectiformes). BMC Genom. 16, 355 (2015).

61. Gong, L. et al. Large-scale mitochondrial gene rearrangements in the hermit crab Pagurus nigrofascia and phylogenetic analysis of the Anomura. Gene 695, 75-83 (2019).

62. Wang, Z. W. et al. Complete mitochondrial genome of Parasesarma affine (Brachyura: Sesarmidae): Gene rearrangements in Sesarmidae and phylogenetic analysis of the Brachyura. Int. J. Biol. Macromol. 118, 31-40 (2018).

63. Inoue, J. G., Miya, M., Tsukamoto, K. \& Nishida, M. Evolution of the deep-sea gulper eel mitochondrial genomes: Large-scale gene rearrangements originated within the eels. Mol. Biol. Evol. 20, 1917-1924. https://doi.org/10.1093/molbev/msg206 (2003).

64. Inoue, J. G. et al. Deep-ocean origin of the freshwater eels. Biol. Lett. 6, 363-366. https://doi.org/10.1098/rsbl.2009.0989 (2010).

65. Chen, J. N., López, J. A., Lavoué, S., Miya, M. \& Chen, W. J. Phylogeny of the Elopomorpha (Teleostei): Evidence from six nuclear and mitochondrial markers. Mol. Phylogenet. Evol. 70, 152-161 (2014).

66. Reece, J. S., Bowen, B. W., Smith, D. G. \& Larson, A. Molecular phylogenetics of moray eels (Muraenidae) demonstrates multiple origins of a shell-crushing jaw (Gymnomuraena, Echidna) and multiple colonizations of the Atlantic Ocean. Mol. Phylogenet. Evol. 57, 829-835 (2010).

67. Johnson, G. D., Ida, H., Sakaue, J., Sado, T. \& Asahida, T. A "living fossil" eel (Anguilliformes: Protanguillidae, fam. nov.) from an undersea cave in Palau. Proc. R. Soc. B Biol. Sci. 279, 934-943. https://doi.org/10.1098/rspb.2011.1289 (2012).

68. Kumazawa, Y. \& Nishida, M. Variations in mitochondrial tRNA gene organization of reptiles as phylogenetic markers. Mol. Biol. Evol. 12, 759-772. https://doi.org/10.1093/oxfordjournals.molbev.a040254 (1995).

69. Loh, K. H. et al. Next-generation sequencing yields the complete mitochondrial genome of the longfang moray, Enchelynassa canina (Anguilliformes: Muraenidae). Mitochondrial DNA Part A 27, 2431-2432 (2015).

70. Loh, K. H. et al. Next generation sequencing yields the complete mitochondrial genome of the Zebra moray, Gymnomuraena zebra (Anguilliformes: Muraenidae). Mitochondrial DNA Part A 27, 1-2 (2015).

71. Perna, N. T. \& Kocher, T. D. Patterns of nucleotide composition at fourfold degenerate sites of animal mitochondrial genomes. J. Mol. Evol. 41, 353-358 (1995).

72. Sudhir, K. et al. MEGA X: Molecular evolutionary genetics analysis across computing platforms. Mol. Biol. Evol. 35, 1547-1549 (2018).

73. Paul, S. \& Wishart, D. S. Circular genome visualization and exploration using CGView. Bioinformatics 21, 537-539 (2004).

74. Nelson, J. S. Fishes of the Word 4th edn. (Wiley, New York, 2006).

75. Xia, X. DAMBE7: New and improved tools for data analysis in molecular biology and evolution. Mol. Biol. Evol. 35, 1550-1552. https://doi.org/10.1093/molbev/msy073 (2018).

76. Shi, W., Kong, X., Wang, Z. M. \& Jiang, J. X. Utility of tRNA Genes from the Complete Mitochondrial Genome of Psetta maxima for Implying a Possible Sister-group Relationship to the Pleuronectiformes. Zool. Stud. 50, 665-681 (2011).

77. Larkin, M. A. et al. Clustal W and Clustal X version 2.0. Bioinformatics 23, 2947-2948. https://doi.org/10.1093/bioinformatics/ btm404 (2007).

78. Hall, T. BioEdit: A user-friendly biological sequence alignment program for Windows 95/98/NT. Nucleic Acids Sympos. Ser. 41, 95-98 (1999).

79. Gerard, T. \& Jose, C. Improvement of phylogenies after removing divergent and ambiguously aligned blocks from protein sequence alignments. Syst. Biol. 56, 564-577 (2007).

80. Gascuel, O. New algorithms and methods to estimate maximum-likelihood phylogenies: Assessing the performance of PhyML 3.0. Syst. Biol. 59, 307-321 (2010).

81. Huelsenbeck, J. P. MrBayes 3.2: Efficient Bayesian phylogenetic inference and model choice across a large model space. Syst. Biol. 61, 539-542 (2012).

82. Posada, D. \& Crandall, K. A. MODELTEST: Testing the model of DNA substitution. Bioinformatics 14, 817-818 (1998).

83. Nylander, J. A. A., Fredrik, R., Huelsenbeck, J. P. \& Nieves-Aldrey, J. Bayesian phylogenetic analysis of combined data. Syst. Biol. 53, 47-67 (2004).

84. Sitnikova, T., Rzhetsky, A. \& Nei, M. Interior-branch and bootstrap tests of phylogenetic trees. Mol. Biol. Evol. 12, 319-333 (1995).

85. Antezana, M. When being "most likely" is not enough: Examining the performance of three uses of the parametric bootstrap in phylogenetics. J. Mol. Evol. 56, 198-222 (2003). 


\section{Acknowledgements}

This study was supported by the National Natural Science Foundation of China (NSFC) (NO.41806156\& No. 31702321)); Zhejiang Provincial Natural Science Foundation of China (No. LY20C190008); Open Foundation from Key Laboratory of Tropical Marine Bio-resources and Ecology, Chinese Academy of Sciences (LMB20201005); Fundamental Research Funds for Zhejiang Provincial Universities and Research Institutes [No. 2019J00048], Starting Research Fund from the Zhejiang Ocean University; Science and Technology Project of Zhoushan (2020C21016).

\section{Author contributions}

K.Z., K.H.Z., Y.F.L. and B.J.L. conceived and designed research. K.Z., K.H.Z., Y.F.L., H.Z., L.G., L.H.J., L.Q.L., Z.M.L. and B.J.L. conducted experiments, analysed data and wrote the manuscript. Authors critically reviewed and approved the manuscript.

\section{Competing interests}

The authors declare no competing interests.

\section{Additional information}

Supplementary Information The online version contains supplementary material available at https://doi. org/10.1038/s41598-021-81622-9.

Correspondence and requests for materials should be addressed to Y.L. or B.L.

Reprints and permissions information is available at www.nature.com/reprints.

Publisher's note Springer Nature remains neutral with regard to jurisdictional claims in published maps and institutional affiliations.

(c) Open Access This article is licensed under a Creative Commons Attribution 4.0 International License, which permits use, sharing, adaptation, distribution and reproduction in any medium or format, as long as you give appropriate credit to the original author(s) and the source, provide a link to the Creative Commons licence, and indicate if changes were made. The images or other third party material in this article are included in the article's Creative Commons licence, unless indicated otherwise in a credit line to the material. If material is not included in the article's Creative Commons licence and your intended use is not permitted by statutory regulation or exceeds the permitted use, you will need to obtain permission directly from the copyright holder. To view a copy of this licence, visit http://creativecommons.org/licenses/by/4.0/.

(C) The Author(s) 2021 